\title{
ANALISIS PEMASARAN MINYAK NILAM DI KECAMATAN LEMBAH MASURAI KABUPATEN MERANGIN
}

\author{
Heroza Firdaus,__syaturriyadhah, Mainif Sepfera
}

Program Studi Agribisnis Fakultas Pertanian Universitas Muara Bungo

herozafirdaus@yahoo.co.id isyaturriyadhah_amin@yahoo.com, mainif_sepfera@yahoo.com

\begin{abstract}
ABSTRAK
Penelitian ini dilaksanakan dari tanggal 12 Januari 2017 sampai dengan 25 Maret 2017 di Kecamatan Lembah Masurai Kabupaten Merangin. Tujuan dari penelitian ini adalah untuk mengetahu pola saluran pemasaran minyak nilam, untuk mengetahui margin pemasaran dan efisiensi pemasaran minyak nilam yang terjadi di Kecamatan Lembah Masurai Kabupaten Merangin.

Metode penelitian yang digunakan adalah metode survey, yaitu metode pengamatan langsung dengan menggunakan kuesioner (Nazir, 2003). Survey dilakukan ke produsen minyak nilam, penyalur minyak nilam dan pengumpul minyak nilam di Kecamatan Lembah Masurai dengan dasar penetapan wilayah secara sengaja karena di Kecamatan Lembah Masurai terdapat minyak nilam yang secara terus menerus di produksi dan memiliki produktifitas tinggi. Metode analisis yang digunakan adalah (1) metode analisis deskriptif, (2) analisis margin pemasaran, (3) efisiensi pemasaran.

Hasil penelitian menunjukkan bahwa pola saluran pemasaran yang terjadi pada pemasaran minyak nilam di Kecamatan Lembah Masurai Kabupaten Merangin adalah satu saluran pemasaran yaitu saluran dua tingkat. Margin pemasaran dalam hal ini margin harga dan margin penerimaan dalam pemasaran minyak nilam di Kecamatan Lembah Masurai Kabupaten Merangin adalah : 1) Margin harga penyalur adalah Rp. 25.000 dan Margin penerimaan Rp. 20.000, 2) Margin harga penyalur adalah Rp. 25.000 dan Margin penerimaan Rp. 17.500. Efisiensi pemasaran ditingkat penyalur sudah efisien karena bernilai diatas $50 \%$ dengan nilai 94,44\% dan efisiensi pemasaran ditingkat pengumpul sudah efisien karna bernilai diatas $50 \%$ dengan nilai $94,74 \%$.
\end{abstract}

Kata Kunci : Analisis Pemasaran, Minyak Nilam, Merangin

\section{PENDAHULUAN}

Dalam konsep agribisnis suatu usaha tidak akan mencapai keuntungan maksimal apabila tidak ditunjang pemasaran yang baik. Kegiatan pemasaran merupakan suatu kegiatan ekonomi yang berperanan menghubungkan kepentingan petani dengan konsumen, baik untuk produksi primer (produk segar), setengah jadi (bahan baku industri) maupun produk olahan jadi (Anindita, 2012). Salah satu produk pertanian yang petensial untuk dikembangkan 
menjadi industri pertanian atau agroindustri adalah minyak nilam dimana minyak nilam biasa digunakan sebagai parfum dan sudah merupakan komiditi ekspor Indonesia. Tanaman nilam merupakan tanaman yang hasil utamanya adalah minyak nilam (minyak atsiri).

Kabupaten Merangin

merupakan produsen tertinggi minyak nilam di Provinsi Jambi dan berdasarkan data dari BPS Kabupaten Merangin (2015) menyatakan terdapat tiga kecamatan yang mengusahakan nilam yaitu Kecamatan Jangkat, Kecamatan Sungai Tenang dan Kecamatan Lembah Masurai. Dan dari tiga Kecamatan tersebut Kecamatan Lembah Masurai merupakan Kecamatan dengan jumlah petani terbanyak ke dua sehingga proses pemasaran lebih banyak terjadi. Untuk lebih jelasnya dapat dilihat melalui tabel 1. berikut :

Tabel 1: Luas Tanam, Produksi dan Jumlah Petani Minyak Nilam per Kecamatan di Kabupaten Merangin Tahun 2014.

\begin{tabular}{|c|c|c|c|c|c|}
\hline NO & \multicolumn{5}{|c|}{ Tahun 2014 } \\
\hline & Kecamatan & $\begin{array}{c}\text { Luas Tanam } \\
(\mathrm{Ha})\end{array}$ & $\begin{array}{c}\text { Produksi } \\
\text { (Ton) }\end{array}$ & $\begin{array}{c}\text { Produktivitas } \\
\text { (Ton/Ha) }\end{array}$ & $\begin{array}{c}\text { Jumlah } \\
\text { Petani } \\
\text { (KK) }\end{array}$ \\
\hline 1 & Jangkat & 207 & 44 & 0,21 & 424 \\
\hline 2 & Sungai Tenang & 903 & 78 & 0,08 & 1.499 \\
\hline 3 & Lembah Masurai & 263 & 43 & 0,16 & 1.152 \\
\hline & Jumlah & $\mathbf{1 . 3 7 3}$ & $\mathbf{1 6 5}$ & $\mathbf{0 , 1 2}$ & $\mathbf{3 . 0 7 5}$ \\
\hline
\end{tabular}

Sumber : Badan Pusat Statistik ( BPS ) Kabupaten Merangin (2015)

Berdasarkan data Tabel 1 maka dapat disimpulkan bahwa Kecamatan Jangkat merupakan Kecamatan dengan produksi dan produktivitas tertinggi $0,21(\mathrm{Ton} / \mathrm{Ha})$ namun jumlah petani terendah 424 (KK), Kecamatan Sungai Tenang merupakan Kecamatan dengan luas tanam dan jumlah petani tertinggi 1.499 (KK) serta produksi tertinggi namun produktivitas terendah $0,08(\mathrm{Ton} / \mathrm{Ha})$ sedangkan Kecamatan Lembah Masurai berada pada produktivitas ke dua dengan produktivitas 0,16 (Ton/Ha) dan jumlah petani cukup

\section{METODOLOGI PENELITIAN}

\section{Tempat dan Waktu Penelitian}

Penelitian ini dilaksanakan di Kecamatan Lembah Masurai banyak $1.152 \quad(\mathrm{KK})$ sehingga memiliki potensi untuk dikatakan sebagai usaha sumber pendapatan masyarakat hal ini yang menyebabkan penulis tertarik untuk meniliti pemasaran minyak nilam di Kecamatan Lembah Masurai. Adapun tujuan dari penelitian ini adalah untuk mengetahui pola saluran pemasaran minyak nilam di lokasi penelitian, untuk mengetahui margin pemasaran minyak nilam di lokasi penelitian dan untuk mengetahui efisiensi pemasaran minyak nilam di lokasi penelitian.

Kabupaten Merangin. Pemilihan tempat dilakukan secara purposive (sengaja) dengan pertimbangan dilokasi tersebut terdapat agroindustri minyak nilam yang secara terus menerus berproduksi 
dan menyesuaikan data dengan jumlah produktivitas yang tinggi dan jumlah petani yang menjadikan usaha minyak nilam sebagai sumber pendapatan dimana Kecamatan Lembah Masurai Kabupaten Merangin merupakan daerah penghasil minyak dengan tingkat produktivitas yang tinggi. Penelitian ini dilakukan mulai 12 Januari 2017 sampai dengan 25 Maret 2017.

\section{Metode Penarikan Sampel}

Populasi dalam penelitian ini adalah pelaku pemasaran minyak nilam di Kecamatan Lembah Masurai Kabupaten Merangin. Total sampel adalah 5\% dari $1.152 \mathrm{KK}$ maka sampel adalah 57 KK, sedangkan sampel utk lembaga pemasaran menggunakan metode snowball sampling yaitu informasi responden berkaitan diperoleh dari informasi responden sebelumnya.

\section{Metode Analisis Data}

Untuk mengetahui pola saluran pemasaran dan perantara lembaga pemasaran di Kecamatan Lembah Masurai Kabupaten Merangin pada tingkat lembaga pemasaran, digunakan analisis deskriptif. Sedangkan untuk mengetahui biaya dan marjin pemasaran ditingkat lembaga pemasaran dalam saluran pemasaran digunakan alat analisis biaya marjin, keuntungan dan marjin pemasaran pada tiap lembaga pemasaran pada berbagai saluran.

1. Margin Pemasaran

A. Marjin Harga

Marjin harga pemasaran merupakan perbedaan harga yang diterima oleh petani dengan harga yang dibayarkan oleh konsumen. Untuk menganalisis pemasaran data harga yang digunakan adalah harga di tingkat petani (produsen) dan harga di tingkat konsumen, secara sistematis dapat dirumuskan sebagai berikut :

$$
\mathbf{M h}=\mathbf{P r}-\mathbf{P f}
$$

Keterangan :

Mh : Marjin harga pemasaran minyak nilam $(\mathrm{Rp} / \mathrm{kg})$

Pr : ( farm price ) Harga minyak nilam ditingkat konsumen $(\mathrm{Rp} / \mathrm{kg})$

Pf : ( retail frice ) Harga minyak nilam ditingkat produsen $(\mathrm{Rp} / \mathrm{kg})$

B. Margin Penerimaan

Marjin penerimaan pemasaran merupakan penjumlahan yang diperoleh pedagang perantara terdiri dari sejumlah biaya pemasaran yang dikeluarkan dan keuntungan yang diterima oleh pedagang perantara, dirumuskan :

$\mathbf{M p}=\mathbf{M h}-\mathbf{B p}$

Keterangan :

Mp : Marjin penerimaan pemasaran minyak nilam $(\mathrm{Rp} / \mathrm{kg})$

Bp : Biaya pemasaran minyak nilam $(\mathrm{Rp} / \mathrm{kg})$

Mh : Margin Harga pemasaran minyak nilam $(\mathrm{Rp} / \mathrm{kg})$

2. Efisiensi Pemasaran

Efisiensi merupakan persentase perbandingan dari harga ditingkat produsen dengan harga ditingkat konsumen.

$$
\text { FS }=\frac{\text { Pf }}{\text { Pr }} \times 100 \%
$$

Keterangan :

Fs : ( Farmer's Shre )Efisiensi pemasaran minyak nilam(Rp)

Pf : ( Fram Price) Harga minyak nilam ditingkat produsen (Rp)

Pr : ( Retail Frice )Harga minyak nilam ditingkat konsumen (Rp) 
Apabila FS $\geq 50 \%$ maka pemasaran efisien, $\mathrm{FS}<50 \%$ maka pemasaran belum efisien (Soekartawi, 2010).

\section{HASIL DAN PEMBAHASAN}

1. Pola Saluran Pemasaran

Pola Saluran pemasaran adalah usaha yang dilakukan untuk menyampaikan barang dan jasa dari produsen ke tangan konsumen yang didalamnya terlibat beberapa lembaga pemasaran yang menjalankan fungsi-fungsi pemasaran (Assauri, 2012), berdasarkan pengertian diatas maka pola saluran pemasaran yang terjadi pada pemasaran minyak nilam di
Kecamatan Lembah Mncumni Kabupaten Merangin adala pola saluran pemasaran yaitu dua tingkat : yaitu produsenpenyalur- pengumpul- konsumen

\section{Margin Pemasaran}

Dalam proses pemasaran minyak nilam senantiasa diharapkan agar tingkat harga minyak nilam tetap tinggi. Proses pemasaran minyak nilam mencakup biaya sejumlah pengeluaran yang dikeluarkan untuk keperluan pelaksanaan kegiatan yang berhubungan dengan penjulan minyak nilam dari petani maupun pedagang

Tabel 2 : Margin Pemasaran

\begin{tabular}{|c|l|r|}
\hline No & \multicolumn{1}{|c|}{ Uraian } & Nilai (Rp/Kg) \\
\hline 1 & Harga Jual Petani Sampel & Rp. 425.000 \\
& Biaya Pengangkutan & - \\
& Total Biaya & - \\
\hline 2 & Harga Jual Penyalur & Rp. 450.000 \\
& Biaya Pemasaran/Transportasi & Rp. 5.000 \\
& Total Biaya & Rp. 5.000 \\
\hline 3 & Harga Jual Pengumpul & Rp. 475.000 \\
& Biaya Pemasaran/Transportasi & Rp.500 \\
& Total Biaya & Rp 7.500 \\
\hline $\mathbf{4}$ & Margin Harga Petani Sampel - Penyalur & $\mathbf{R p . 2 5 . 0 0 0}$ \\
\hline $\mathbf{5}$ & Margin Harga Penyalur - Pengumpul & $\mathbf{R p . 2 5 . 0 0 0}$ \\
\hline $\mathbf{6}$ & Margin Penerimaan Penyalur & $\mathbf{2 0 . 0 0 0}$ \\
\hline $\mathbf{7}$ & Margin Penerimaan Pengumpul & $\mathbf{1 7 . 5 0 0}$ \\
\hline
\end{tabular}

Sumber : Analisis Data Penelitian 2017

Berdasarkan Tabel 2 yang merupakan margin pemasaran yang terdiri atas margin harga dan margin penerimaan dari rantai pemasaran minyak nilam diKecamatan Lembah Masurai Kabupaten Merangin maka dapat dijelaskan beberapa hal sebagai berikut :

1. Margin Harga Petani Sampel - Penyalur

Mh $\quad=$ Pr - Pf
$\mathrm{Mh}$

- Rp. 425.000

Mh

$=$ Rp. 450.000

Keterangan

$\mathrm{Mh}$

$=$ Rp. 25.000

Harga

Pr : Harga Jual

Penyalur

Petani

Pf : Harga Jual

2. Margin Harga Penyalur Pengumpul 


\begin{tabular}{|c|c|c|}
\hline & Mh & $=\mathbf{P r}-\mathbf{P f}$ \\
\hline & $\mathrm{Mh}$ & $=$ Rp. 475.000 \\
\hline \multicolumn{3}{|c|}{ - Rp. 450.000} \\
\hline & Mh & $=$ Rp. 25.000 \\
\hline & Keterangan & \multirow[b]{2}{*}{ Margin } \\
\hline & Mh & \\
\hline \multicolumn{3}{|c|}{ Harga } \\
\hline & $\operatorname{Pr}$ & : Harga \\
\hline \multicolumn{3}{|c|}{ Pengumpul } \\
\hline & $\mathrm{Pf}$ & : Harga Jual \\
\hline & \multicolumn{2}{|l|}{ Penyalur } \\
\hline \multirow[t]{7}{*}{3.} & \multicolumn{2}{|c|}{ Margin Penerimaan Penyalur } \\
\hline & Мp & $=\mathbf{M h}-\mathbf{B p}$ \\
\hline & $\mathrm{Mp}$ & \multirow[t]{2}{*}{$=$ Rp. 25.000} \\
\hline & Rp. 5.000 & \\
\hline & Мр & $=$ Rp. 20.000 \\
\hline & Keterangan & $:$ \\
\hline & $\mathrm{Mp}$ & Margin \\
\hline \multicolumn{3}{|c|}{ Penerimaan } \\
\hline & $\mathrm{Mh}$ & Margin \\
\hline \multicolumn{3}{|c|}{ Harga Penyalur } \\
\hline & $\mathrm{Bp}$ & $:$ \\
\hline & \multicolumn{2}{|c|}{ Pemasaran Penyalur } \\
\hline \multirow[t]{7}{*}{4.} & Margin & Penerimaan \\
\hline & $\begin{array}{l}\text { Pengumpul } \\
\mathbf{M p}\end{array}$ & $=\mathbf{M h}-\mathbf{B p}$ \\
\hline & $\mathrm{Mp}$ & \multirow[t]{2}{*}{$=$ Rp. $25.000-$} \\
\hline & Rp. 7.500 & \\
\hline & Мp & $=$ Rp. 17.500 \\
\hline & Keterangan & $:$ \\
\hline & $\mathrm{Mp}$ & Margin \\
\hline \multicolumn{3}{|c|}{ Penerimaan } \\
\hline & $\mathrm{Mh}$ & Margin \\
\hline \multicolumn{3}{|c|}{ Harga Pengumpul } \\
\hline & $\mathrm{Bp}$ & Biaya \\
\hline & Pemasaran I & igump \\
\hline
\end{tabular}

\section{Efisiensi Pemasaran}

Efisiensi pemasaran disini dibahas efisiensi ditingkat penyalur dan ditingkat pengumpul karena melakukan aktivitas pembelian dan penjualan dalam pemasaran minyak nilam.

1. Efisiensi Pemasaran Penyalur

$$
\begin{aligned}
\mathbf{F S} & =\underline{\mathbf{P f}} \times \mathbf{1 0 0} \% \\
\mathrm{FS} & =\underline{425.000} \times 100 \%
\end{aligned}
$$

$$
\text { FS } \quad=\quad \mathbf{9 4 , 4 4 \%}
$$

Berdasarkan hasil diatas maka dapat disimpulkan bahwa efisiensi pemasaran ditingkat penyalur sudah efisien karena bernilai diatas $50 \%$ dengan nilai 94,44 \%. Kesimupulan bahwan proses pemasaran minyak nilam di Kecamatan Lembah Masurai sudah Efisien.

Efisiensi Pemasaran Pengumpul

$$
\begin{aligned}
\text { FS } & =\frac{\text { Pf }}{\mathbf{P r}} \mathbf{1 0 0} \% \\
\text { FS } & =\frac{450.000}{475.000} \times 100 \% \\
\text { FS } & =\mathbf{9 4 , 7 4 \%}
\end{aligned}
$$

Berdasarkan hasil diatas maka dapat disimpulkan bahwa efisiensi pemasaran ditingkat pengumpul sudah efisien karna bernilai diatas $50 \%$ dengan nilai $94,74 \%$.

\section{KESIMPULAN DAN SARAN}

\section{Kesimpulan}

1. Pola saluran pemasaran yang terjadi pada pemasaran minyak nilam diKecamatan Lembah Masurai Kabupaten Merangin adalah satu pola saluran pemasaran yaitu saluran dua tingkat.

Petani $\rightarrow$ Penyalur $\rightarrow$ Pengumpul $\rightarrow$ Konsumen

2. Margin pemasaran dalam hal ini margin harga dan margin penerimaan dalam pemasaran minyak nilam diKecamatan Lembah Masurai Kabupaten Merangin adalah : 1) Margin harga penyalur adalah Rp. 25.000 dan Margin penerimaan Rp. 20.000, 2) Margin harga penyalur adalah Rp. 25.000 dan Margin penerimaan Rp. 17.500. 
3. Efisiensi pemasaran ditingkat penyalur sudah efisien karena bernilai diatas $50 \%$ dengan nilai $94,44 \%$ dan efisiensi pemasaran ditingkat pengumpul sudah efisien karna bernilai diatas 50 $\%$ dengan nilai $94,74 \%$.

\section{Saran}

1. Untuk penelitian kedepannya mungkin bisa tambahkan ruang lingkup yang lebih luas dengan menambahkan konsumen.

2. Petani sampel perlu meningkatkan mutu dengan mengolah tanaman nilam mengikuti aturan bercocok tanam yang baik dari segi jumlah pupuk dan perawatan.

\section{DAFTAR PUSTAKA}

Anindita. R. 2012. Pemasaran Hasil Pertanian. Papyrus. Surabaya.
Assauri. 2012. Pemasaran: Prinsip dan Kasus. BPFE. Yogyakarta.

Badan Pusat Statistik (BPS) Jambi. 2015. Jumlah Produksi Pertanian. BPS. Provinsi Jambi.

Badan Pusat Statistik (BPS) Kabupaten Merangin. 2015. Jumlah Produksi Pertanian. BPS. Kabupaten Merangin.

Kolter. P. 2007. Dasar-dasar Pemasaran. Ghalia Indonesia. Jakarta.

Nazir. M. 2003. $\Lambda$ Penelitian. Ghalia Jakarta.

Soekartawi. 2001. Agribisnis. Teori dan Aplikasinya. PT Raja Grafindo Persada. Jakarta. 